
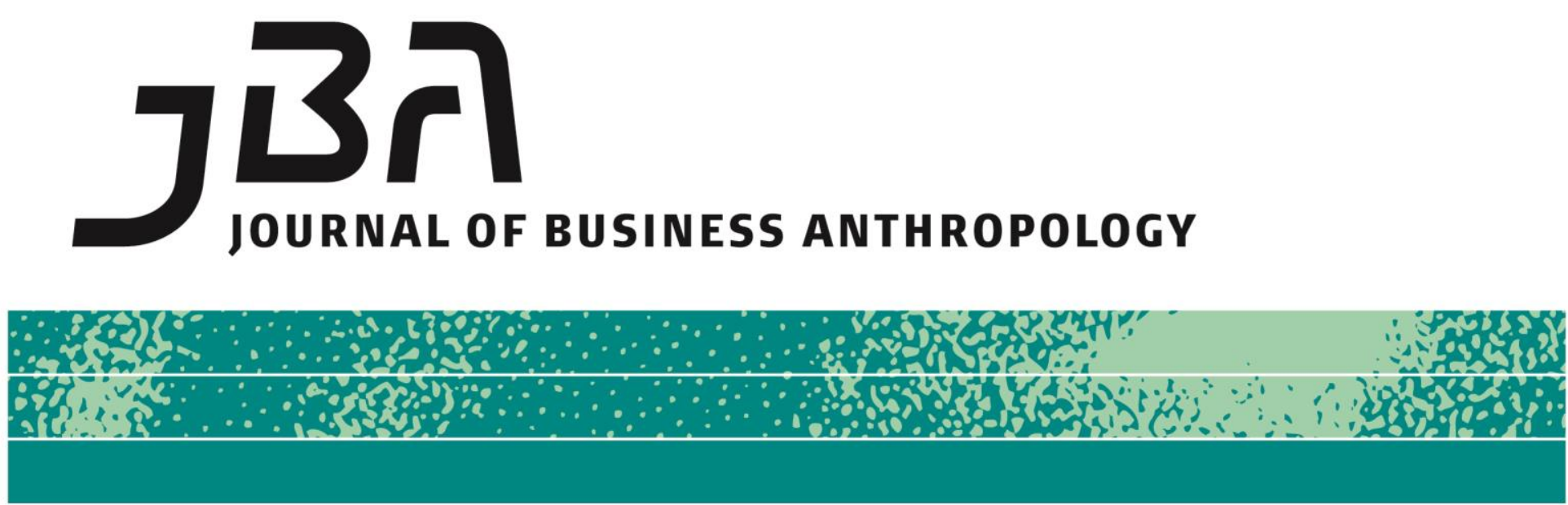

\title{
Essay
}

\section{Random in the time of social media}

\author{
Michael Donovan
}

"Fig _ fearsome" is James' instagram handle. It comes from a fig tree that he passes every morning in Astoria on his way to the subway. This tree is a token of things he likes about his neighborhood, its humble beauty, immigrant working class spirit, the "random" signs of diversity that give the place its energy.

Instagram for James is the perfect mobile medium to capture such connections to place, and the surprising events and things that bring life into focus (and bring James to life). A video snip of seals playing in their Central Park pool during a blizzard, hash tag "snow day," that reads "seals don't care-everyday is a snow-day," conveys such a moment of animation. A landscape photograph of fire escapes covered by snow, hash tag "snow-globe," supplies a whimsical vignette of this year's neverending winter.

James likes Instagram because it combines a quickness, and lightness, and playfulness with "authenticity." It comes from the heart, these visual missives that show his eye for the world, not too heavy, perhaps even silly or fun, with a tinge of irony. And undeniably styled. In the style, he suggests, of New Yorker cartoons..."pitch perfect." This attention to composition, the combination of crafted image or video and just the right text, is perhaps best described as platform specific, a case of

Page 1 of 7

JBA 3(2): 246-252 Fall 2014

(C) The Author(s) 2014 ISSN 2245-4217

www.cbs.dk/jba 
design-driven evolution of user-generated conventions.

James can certainly communicate these conventions crisply. His professional skills as a literary publicist and his relatively deep experience with social media no doubt come into play. Instagram, as he puts it, presses us to "find creative ways to convey you living your life." It is a channel for sending and receiving edited bits of subjectivity, creatively curated little bits of the world as we encounter it.

Like Twitter, Instagram's short form and mobile interface (it is almost always activated via the screen of a smart phone), makes for a particular kind of sociability, relatively immediate and ephemeral, but also-and here it is often different from Twitter-quite intimate. It is the gestalt of a photo with its emotional heft, rather than the prickly parsing of text, that distinguishes the two media. Both give us a life in motion, a life unfolding, one more akin to Maurice Chevalier strolling down the boulevard with his characteristic insouciance (Twitter), the other more emotionally available and in tune with the felt sense of things (Instagram). And both open up a space for the "random," the happened upon, the surprising, the unpredictable, that social media are prone to pounce upon and endow with meaning, and that says: "See, I am engaged in this quirky, lively world out there; I am seeing and translating these encounters in creative ways, and I am sharing it with you all."

This is, to my ear, is a novel usage of random. It seems to be tied to digital life, and new forms of connectedness to the world and to one another. But let's tread cautiously here. The conviction that we should keep our hearts open, even cultivate an acquisitive alertness to what the world can teach us (if we just look closely), certainly predates digital times. The random, insofar as we allow it as a synonym for the surprising or unexpected, has long been recognized as a key for discovery and integration, a spark that enables us to pull things together in fresh or novel ways. Ontologically this could be (and has been) extended to all kinds of patterned meaning. Reality, so far as our minds can map it, is hidden in plain sight-well, maybe with the aid of a proton accelerator.

More prosaically, the mental and spiritual jostling that can take place when we stumble upon the "random" might teach new ways of seeing and understanding ourselves and the world. So, falling accidentally (aka randomly) on an interstitial landscape of snow-covered fire escapes between apartment buildings in Queens reveals to our protagonist James that "the world is a snow globe," transforming-at least for a moment-the head down, collar turned-up, grind of an especially nasty winter in the city into something with magic around it.

While not uniquely so, social media have the power to externalize such discoveries. Operationally, these media (Instagram, Twitter, Snapchat, Vine, You Tube, to name a few) ask us to move quickly from apperception to composition to communication. Of course, the vast, vast, vast measure of such posts is not world rocking by anyone's reckoning. 
But the facility social media show for articulating discoveries, chiefly self discoveries, however quotidian, is certainly a defining feature. And so, I venture, we can point to the importance and frequency of the random in the native language of social media.

Lexically it's fair to ask what is going on here? Is this a case of a word's meanings being twisted by promiscuous and ill-informed speakers who, by the way, always win out in the end? As the linguistic philosopher Ludwig Wittgenstein put it, a cow is what the public calls a cow. Or is something more interesting at play? Is there something intrinsic about digital life that gives the random the space to thrive?

The truly random is illusive, as any cryptographer or advanced mathematician will tell you. But the apparently random has always had a magic to it, a bright side and a dark side. Think of the apparent randomness of being hit by a rare form of cancer, or struck by lightning, or being on the next flight that didn't scoop up a flock of seagulls in its engines and then slam into a mountain. Probability theory really doesn't help us with the moral, theological, or magic-laden questions of why here and now, or more pointedly why me. So the random retains a special juju in our imagination.

It's what we do when we encounter the apparently random that makes things interesting: or, more narrowly, how we bring the random into a meaningful relationship with our lives. Life's everyday experiences are, in a probabilistic way, a regression towards the mean, a statisticallyweighted shift away from the exceptional and towards the norm. How we react to things that randomly beset us then become the most vivid and often poignant articulations of who we are. The "magic" of the random is how it animates us, how it goads us to find meaning in a deterministic world that we really don't know a lot about and really, really, don't control.

So back to our question about social media. Why does the word flourish here, and what kinds of things does it index? Perhaps the most familiar usage is oddly normative, a lexical marker for things out of place, e.g. the "random" post, or person, or happening that doesn't belong in our web-centered social circles. Viewed narrowly, the social firewalls of our Facebook or Instagram or Twitter accounts are famously easy to breach. Viewed systematically, this seems to be the nature of digital spaces. Boundaries are continually shifting, and the inside-outside geography of our communities is unstable.

Calling out the random then becomes a way to engage a digital world that is contingent, unpredictable, always in motion. Perhaps no more so than the material world with which it is entwined. But to our cultural senses digital life is speed; it happens at a gallop, and this hyper kinetic nature is both compelling and subversive-in fresh vernacular, random. A look at the deep etymology of the word may show us why it resonates with our current condition. Random comes from Old French 
randon, "rush, disorder, force, impetuosity," which itself comes from randir, "to run fast" (or gallop), which is derived from Frankish *rant, "a running" or some other Germanic source, Old High German rennen "to run." (see http://www.etymonline.com/index.php?term=random)

There are two sides to random's linguistic coin. There is the antinormative random which jibes with common usage, e.g. the haphazard, directionless, "without definite aim or purpose"-ergo, disorderly or out of place random, AND the happened upon, surprising, unpredictable random which, as we have seen, can become a spark for synthesis and new understanding. This second-should we call it recently coined?-random is much more interesting to me; like the Hindu god Shiva, it is both world destroyer and world creator.

This new sense and feeling for the random is emerging as a powerful force in digital life. It provides a patois for marking, and riffing on the mobility and fast rhythms and simultaneity of our days. When we are "on" Instagram or Twitter, or other social media platforms, we have our feet in different spaces at once: the embodied space of a subway platform, or our beds, or a beach in Honduras, or wherever we happen to be, AND the shared digital space of any social media platform we engage (figuratively touch) through a device we hold in our hand, or purse, or hip pocket.

Social media have been instrumental in braiding together these two spaces (the embodied and the digital.) Such spatio-temporal jujitsu can result in trivial, even oppressive, engagements (who really wants to engage with columns of posts from a friend's trip to Norway?). But it does seem indisputable that some profound changes are happening in the ways that we are making meaning, collectively and singularly from life. Awareness of the random, calling out the random, its use and frequency in the native language of social media, reflects this shift in consciousness.

Anchoring the new values and meanings that we give to the random are the semantic and expressive roles it plays connecting embodied and digital spaces and activating social relationships "across" these spaces. When we grab a piece of "random" life and share it (post, like, re-post) on social media, we are forging such connections. It is odd to of think of it this way, but what social media bring to social life is the ability to grab and encapsulate a bit of embodied experience on the fly, and distribute it to variously dispersed others who share digital space with us. This entwinement and experience of participation becomes the germ for creating and sustaining community. The speed and ephemeral nature of these captures are crucial to understanding their heightened social meaning. They take us "accidentally" (perhaps unselectively) into one another's lives. This gives the random a kind of sacred power, the special juju we mentioned earlier. In capturing the effervescence of life, the random activates and enlivens human relationships.

Let's settle down a bit with a concrete illustration. During a recent 
search on Instagram for posts with the hash tag "random," I (randomly) found this sweet missive from one Lucy Waters, a young woman apparently on holiday in Istanbul at the time. The accompanying text refers to a "random man" who seems to be a playful Turkish guy she encounters on the street, though the entire encounter could be classified as random in the language of Instagram or other social media.

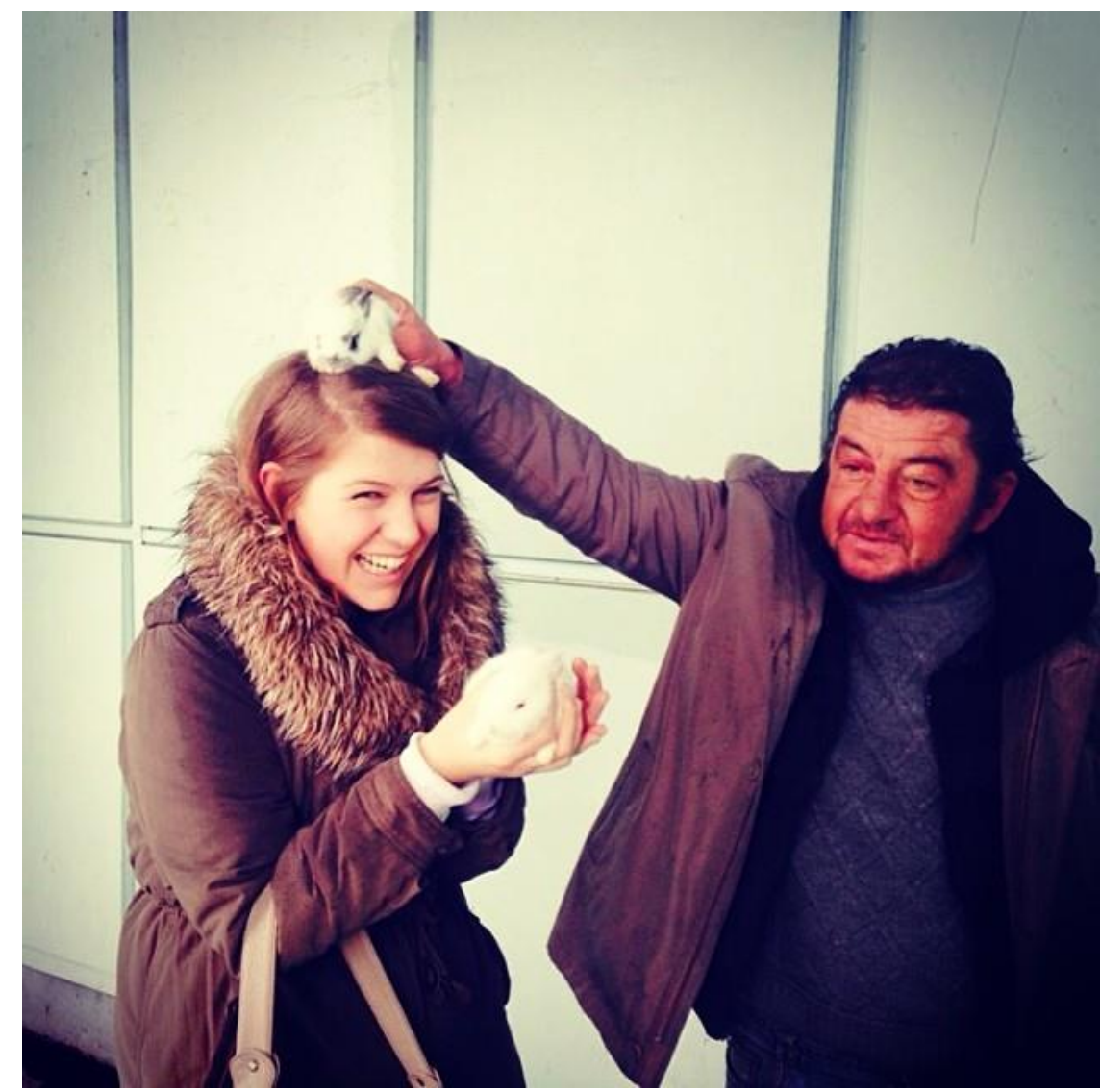

Figure 1: A random man put a bunny on my head \#bunnies \#random \#weird \#lovethepic \#holiday \#Istanbul

She is having a touristic adventure for sure. We can't imagine she went off that day looking for bunnies. No, she stumbled on them, in what we might guess is an Istanbul market. Probably in her native land there are no bunnies for sale on the street. She picks one up and cradles it and all its cuteness in her hands. This is \#weird. The whole event is \#weird (and random). Then, in my mind's eye, a third party (her travel mate? a passer by?) steps back to frame a picture, \#lovethepic, at which point, "a random man" put a bunny on her head. Well HOW was he \#random? He is likely a rabbit breeder and seller with a wholly different connection to bunnies than she. Playfully, it seems mischievously, he puts the bunny on her head. The picture captures something of the cultural distance between them, which-of the two-he seems most conscious of. It is just visible on his face, and in the gesture and attitude of his body. She becomes bunny- 
like with her fresh face and fur collar, and he, with his craggy face and rough coat, is momentarily duplicitous in this transformation. This becomes a quintessential \#holiday \#Istanbul moment: its randomness wrapped up in the happened upon, ephemeral and momentarily transformative experience that Lucy gamely posted on Instagram.

There is one yawning problem with this usage of random. It can eclipse any sense of situatedness to such encounters. Our Turkish rabbit dealer and his "bunnies," if you accept my guess about his identity, are most likely part of an informal market economy. Perhaps they have a permanent stall at a particular market place. Perhaps selling rabbits is a family business, or something you do when you are down on your luck. Are bunnies an important source of protein in working class Istanbul? How are they cooked? As in Greece, cacciatore style? Do they trigger culinary nostalgia for a simpler country life among Turkish city dwellers?

Our Turkish friend and his rabbits could only be viewed as random from a naïve touristic eye. Well, this could raise other knotty issues such as Orientalism and the "Western touristic gaze." But without even going there, simply labeling the "man" as "random" decontextualizes this encounter and blocks a path to further discoveries and connections. There is no small bit of irony at work here. As an idiom to convey self discovery, a synonym for the surprising or unexpected, more broadly as an idiom to communicate the "aha's" of social media, the random performs this curious semantic trick of decontextualizing and then recontextualizing happenings or events, those stumbled upon moments of life that get shared within ones' social circle. It is here that the random is working both as world destroyer and world creator.

The random gains its power and meaning as it is mobilized in building a voice and a shared sensibility. The random gets woven, in a participatory sense, into collective experience. This activity of capturing experience and making it one's own or, one could say finding one's voice, is always a collaborative thing. It is, of course, quintessentially human. But, as we have seen, it can both expand and impoverish our connectedness with the world around us. Social media seem to be a particularly powerful contemporary platform for doing this. There is something giddy and fresh going on here in these apperceptions of the random. It is hard not to respond fondly to Lucy Waters' post. I just hope she got a chance (après instagram post) to visit our Turk's house for a dish of rabbit pie. 
Michael Donovan holds and Ph.D. in Anthropology from New York University and works for Partner Practica Group LLC in New York, where he specializes in strategy consulting, marketing communications, branding, public policy and innovation. He has had the good fortune to bring his skills and experience as an anthropologist to an incredibly diverse set of projects. His work, which typically provides a fresh look at the cultural spaces inhabited by categories, brands, products and services, has yielded notable successes in new product development, retail design, portfolio management, audience development, messaging and strategic planning. He may be reached at mdonovan@practicagroup.com 